\title{
The clustered nature of the sustainable development of the region (using the example of the South of Russia)
}

Irina Fomina

South Russia Institute of Administration - the Branch of the Russian Presidential Academy of National Economy and Public Administration, Faculty of Management, Chair of Economics, Finance and Nature Management Rostov-on-Don, Russia fominamail@mail.ru

\author{
Tatiana Kushnarenko \\ Don State Technical University, \\ Faculty of Information and Economic Systems, \\ Chair of Accounting, Analysis and Audit \\ Rostov-on-Don, Russia \\ fominamail@mail.ru
}

\begin{abstract}
The analysis of production and economic activities of enterprises suggested considering and proposing a new integration form of interaction of enterprises in the region. The article is devoted to the identification of the prerequisites for the formation and development of clusters in the South of Russia. It is shown that clustering will make it possible to increase the investment attractiveness of both the individual industry and the region as a whole.
\end{abstract}

Keywords - clustering, agro-industrial cluster, non-raw scenario of development, multi-regional economy of the region, import substitution, potential of the region

\section{INTRODUCTION}

Reforming the economy is the central task of the country's structural policy. At the regional level, it should be decided in the format of technological modernization of the entire production and economic complex. The most perspective direction is the creation of new integration forms of the spatial organization of production and economic activity on the basis of clusters. Their creation will make it possible to use the existing potential of manufacturing and processing industries, which form the basis of the non-primary sector of the economy. In turn, the formation of clusters that unite enterprises of all phases of the production and technological cycle from the production of raw materials to the creation of a high-tech final product with a high share of added value and as a result it will ensure the sustainable accelerated development of the regional economy.

\section{MATERIALS AND Methods (Model)}

Research methods included dialectics and analytics, system analysis, induction and deduction, mathematical modeling in economics, statistics, expert evaluation, scenarios, brainstorming, etc.

\section{RESULTS AND DISCUSSION}

The regions of the South of Russia are traditionally characterized by a multi-level economy with a predominance of agro-industrial enterprises. In line with the state economic policy aimed at the formation of a non-resource model of economic development, it seems necessary to modify the structural production and economic system of the southern regions of the country.

Two main factors of regional development should be noted.

The first of them is that there are traditionally many socioeconomic ways in the southern regions, including archaictraditional ways of ethnic Economics in the republics of the North Caucasus. The involvement of all types of resources (raw materials, material, labor, financial) in the process of technological modernization of the production potential of the southern regions of the country will create a basis for the formation of a model of non-resource development of the economies of these regions. In turn, this will ensure sustainable development of the southern macroregion as a whole.

The second factor is that the development of integration and cluster forms of agro-industrial production is a necessary condition for the creation of high-performance clusters with a closed curcuit production and economic cycle. This type will fully comply with the paradigm of innovation and resource development, focused on the creation of high-tech food and non-food products (textiles, footwear, wool, down, fur, leather, etc.) of agricultural origin. Closed-curcuit clusters will reduce the share of the commodity sector in regional markets and significantly reduce transregional exchange. 
The implementation and the of the non-resource scenario of economic development process of import substitution is well traced by the example of the organization of production of agricultural raw materials in the largest in the South of Russia zones of activity of agro-industrial complexes of cluster type. Tere are some examples of such companies as joint stock companies "Yug Rusi" (Rostov region), "Agrocomplex" (Krasnodar region), where the entire technological process is carried out directly from the cultivation of agricultural raw materials to the production of the finished product and its implementation through a specialized trading network.

The process of clustering in agriculture has objective reasons.

Firstly, disparate producers do not have the ability to react quickly to changes in market conditions (lower demand for products, changes in the conditions of its transportation, the dynamics of market prices, etc.).

Secondly, there is no possibility of acquiring credit resources in sufficient volumes and at specific periods of the agricultural cycle to address current and investment issues.

Thirdly, the high dependence on prices and tariffs for fuel and other energy resources, which significantly increases the costs of agricultural producers.

The creation and functioning of cluster-type agroindustrial complexes will allow to solve the main tasks of the country's agro-industrial policy, in particular:

- to provide technological modernization of production;

- to improve the quality of raw materials and manufactured products;

- reduce the cost of raw materials and finished products;

- reduce the cost of raw materials and finished products;

- to meet the needs of the population in high-quality and affordable food.

Simultaneously with the solution of these tasks, the investment attractiveness of cluster-type agro-industrial companies will grow, the professionalism of the personnel of the agricultural and processing industries will increase, as well as fair competition in the markets for products will develop.

Enterprises included in the agricultural cluster, obtain a number of advantages compared to the non-associated producers, due to the ability of the cluster to focus in and around all types of resources. They are financial, labor, investment, innovation, information, technology. We list the most significant advantages of clustering in the agro-industrial complex.

The use of information and communication technologies contributes to changes in the sectoral structure of the agroindustrial complex, creates new conditions for competition, creates conditions for the development of new types of business.

Concentration of resources and coordination of interaction within the boundaries of one or more regions contributes to an increase in the rate of profit (or profitability) of enterprises participating in the cluster. This generally affects the improvement of performance indicators of administrativeterritorial entities, in which the enterprises of agro-industrial clusters are located.

Development of agro-industrial cluster in the form of closed technological chains allows to provide the maximum loading and efficiency of use of production capacities for the purpose of receiving a final product. Introduction of intensive technologies of production of agricultural products give the Foundation for reducing costs and optimization of taxation of enterprises of the cluster.

Introduction of information and communication technologies in the management of agro-industrial cluster creates conditions for effective interaction with the regional and municipal authorities in order to implement the policy of import substitution.

Joining the agro-industrial cluster provides the personnel of enterprises with professional growth, access to new methods of work and technologies, stimulates flexibility and develops the ability to react quickly to changes in the market sphere.

The most important direction of the development of the agro-industrial complex is the provision of food independence for basic food products, the production of which can be achieved through the use of domestic raw materials on its own production base. Government policy of import substitution is meant to support the agricultural enterprises, the imposition of restrictions on the import of food, the growth of trade between regions, the implementation of structural sectoral shifts in the agricultural sector, the development of production relations on the basis of the technological division of labour, increase of export potential. So, import substitution should be considered as an important part of the state foreign trade policy and at the same time as a tool for regulating national food security.

Cluster economy gains the increasing popularity in the world as the new type of industrial consortia provides high efficiency to both business, and the state. Close attention to development of clusters is paid by such international organizations as the Economic Cooperation Organization (OSER), the World Trade Organization (WTO), the European Union. Within the last one the possibility of formation of the all-European model is considered which realization will strengthen national and regional initiatives that as a result will increase competitiveness of the companies and the countries.

For the first time the idea about the opportunities and advantages arising when merging the separate companies was stated by the English economist Alfred Marshall, the founder of "the Cambridge school" in the work "Principles of Economic Science" (1890). On the basis of the conducted research of industrial regions of Great Britain A. Marshall has described the synergetic effect reached at association and increase in specialization of small enterprises. In modern terminology A. Marshall's idea can be presented in the form of creation of clusters with rather extensive intercompany division of labour. [1]

In modern economy his ideas has been continued and successfully developed by Michael Porter. The analysis of conditions of development and activity of 100 most 
competitive groups of large, medium-sized and small enterprises, he has come to a conclusion that at achievement of a certain high level of competitiveness in the world market one of groups begins to extend the influence on the immediate environment, forming thereby steady reliable network of suppliers and consumers. [2] As a result, participants of groups in the course of interaction try to obtain decrease in cumulative expenses, increase in productivity of work, increases in competitiveness, otherwise, prove in practice a cluster phenomenon.

For justification of cluster approach as integration form of production economic activity of the enterprise it should be noted that this approach is based on policy of non-oil development of national economy in the conditions of multiformity of her regional systems. According to L.G. Matveeva, due to synergetic effect of the existing economic ways, the result can have both static, and dynamic character. [3] In this regard systematization of classification signs will allow to understand better the determinants defining differences in various types of economic activity for the subsequent development of effective levers of stimulation of regional development.

N.P. Ketova and V.N. Ovchinnikov point to the importance of positive influence of synergetic effect of multiformity on dynamic development of agro-industrial complex. According to them, for modern researches of economic ways of regional economies most often such characteristics are used as: the scale of production and financial activity (the prevailing size of the enterprises), form of ownership, width of coverage of sales markets, existence and the nature of integration interactions of economic entities, key branches in region economy, the prevailing technologies that are used in production. [4] Ethno economic, small-scale, private and corporate, state ways can become interesting classification signs of economic ways.

According to the author's concept, [5] strategy of the advancing development of the real sector of regional economy for the manufacturing enterprises are based on the conceptual and specific principles on the basis of which adaptive mechanisms and tools of support of decision-making on creation and formation of clusters in the conditions of multiformity are developed. The research of a concept of multiformity, the analysis of factors and conditions which have led to economic disintegration of regional space in agroindustrial complex have allowed to formulate the concept of transition to the non-oil scenario of development of regions with multistructure economy.

In the conditions of creation of clusters the regional system synthesizes in itself economic, social, technological and political aspects for the purpose of formation of the non-oil scenario of development of economy of the region, focused on the balanced development of all a component. When forming an agro-industrial cluster in the region with multistructure economy it is necessary to involve as much as possible the potential of each existing way in processes of the high-quality changes leading to economic growth. At the same time the combination of various ways provides the synergetic effect of integration of economic, resource, innovative reproduction and functional, organizational and administrative capacities of regions. It allows to unite separate components of social and economic development of regions in the complete system focused on implementation of the non-oil scenario of development. [5] Regional strategy have to be aimed at formation of "multi-scale" structure of economy of the region taking into account primary use of cluster forms of interaction of business and governing bodies that as a result will provide integration of potentials of separate types of ways.

On the basis of a research of the available resources and potential opportunities it is possible to speak about real modernization of economy of regions of the South of Russia. It is necessary to use qualitative advantages of multiformity for this purpose which can provide formation of multistructure economy that, in turn, will become an important factor of modernization process in the southern regions of the country. As the priority directions it is necessary to choose spheres of economic activity which modernizations will be based on integration of raw and non-oil potentials. Such approach will guarantee multiplicative effect in the form of increase in production in allied industries that most quickly can be shown in agro-industrial complex of the South of Russia.

Theoretical-conceptual approach to formation of the strategy of development for the non-oil sector of economy in the conditions of a multiformity of regional system of economy was offered in a dissertation research [5] For development of concrete mechanisms of modernization of economy of the region on the basis of use of advantages of multiformity of economy it is necessary to allocate basic components of regional potential, to give their definitions, to develop estimated indicators for each of them. In other words, it is necessary to create estimated criteria which would allow to apply quantitative criteria at decision-making at the regional level.

Four components of potential were presented in a research: technological, labour, investment, the potential of organizational and administrative interactions, characterize multiformity of regional economy. This list, in our opinion, should be specified. First, technological potential can be designated as production and technological potential more precisely. Secondly, labour potential should be considered taking into account influence of demographic factors. Thirdly, investment potential can be investigated mainly from a position of his innovative component then it has to be called as investment and innovative potential. Fourthly, the list should be added with such elements as resource and raw, infrastructure and financial potential, each of which has to be characterized by the indicators. For example, assessment of resource and raw potential has to characterize security of economic activity in the region by balance stocks of main types of natural resources. Assessment of infrastructure potential has to reflect the level of development in the region of production, economic and social infrastructure. The characteristic of financial potential can be estimated taking into account the following indicators: size of tax base, level of profitability of the enterprises, level of income of households of the region, etc. 
Continuing a subject of formation of clusters as integration form of production economic activity, we refer growth of efficiency and the outputs which at the same time isn't "frontal" to the positive moments. Noted growth is peculiar only to a separate part of the agro-industrial enterprises. For development of the agrarian sector of economy the state has to interfere actively with emergence of crises of overproduction of products, stimulate the actions directed to support of development of the manufacturing enterprises. Rationally planned regional policy concerning development of agroindustrial complex has to be directed, on the one hand, to increase in efficiency and competitiveness of regional producers, on the other hand, to food self-sufficiency. The policy in the sphere of agrarian and industrial complex has to have long-term character and a vector of her development has to be created according to the strategies of social and economic development of regions. At the same time "program projects though in general are also focused on development of the periphery, however, there aren't any ideas of how problems of territories with backward ways will be solved and what mechanisms and technologies will promote implementation of the innovative scenario of their development. Thus, the developed strategies don't consider all capacity of regions as don't assume realization of potential of multiformity of his economies and obtaining possible synergetic and multiplicative effects". [6]

\section{CONCLUSION}

Results of a research of a problem of a clustering as integration form of production economic activity demonstrate that clusters are a point of economic growth not only separately taken branch, but also the region in general. It confirms need of fixing of the purposes, mechanisms, tools and technologies of formation and creation of clusters taking into account new cluster form of relationship which will promote stimulation of innovative interests, development of progressive technologies, strengthening of synergetic effect of integration interactions of the "centre and the periphery" based on complementarity of capacities of territories of the region.

The manufacturing enterprises entering a cluster become more competitive and investment and attractive, have an opportunity on intra cluster channels freely to communicate, to introduce various look progressive technologies quicker. Being a point of economic growth, the cluster promotes intensive integration interaction of the centre and the periphery. Not only earlier known companies become participants of a cluster, but also farmers, representatives of private partnership, individual entrepreneurs and other small business entities are involved in a cluster. For such participants the most important issues of survival in the market are resolved: existence of a source of raw materials, production modernization, sales market of production, attraction of investments and another. In other words, participants of a cluster in development of interaction and rapprochement of interests gradually overcome dissociation, inertness and isolation on internal problems that well influences growth of their technological level and competitiveness, and as a result, appeal of the region in general. [5] The consensus of economic interests taking into account multiformity of the region has to be the basis for interaction of participants of an agro-industrial cluster of regions. Increase in efficiency of cluster approach requires improvement of regional institutional base. At the same time it is necessary to allocate a number of major strategic problems which solution assumes changes of system character within program and target approach to formation of the directions of regional economic policy within formation and creation of an agro-industrial cluster:

- flexible institutional "linking" of resources of modernization of regions with various types of ways for innovative development of the real sector;

- development of modern infrastructure of interaction of economic entities of various types of technological ways;

- formation of innovative and production clusters in the region with involvement in their structure of capacity of territories with various ways;

- overcoming institutional deficiencies, creation of the competitive environment for development of partnership of participants of a cluster. [5]

Target programs of development (federal, regional, branch) have to become instruments of realization of the specified directions. In this regard further development of work on a regional strategizing is necessary where a key priority is formation of mechanisms of realization of potential of multiformity of territorial economies and their integration into process of creation of clusters.

\section{References}

[1] A. Marshall. Principles of economic science. / A. Marshall. Moscow: Progress, 1993.

[2] M. Porter. Competitive strategy: the Technique of the analysis of branches and competitors. 2015.

[3] Ivanov A.V., Matveeva L.G., Chernova O.A. Capitalization of resources of the industrial enterprise as a part of a cluster in strategy of innovative development // The Engineering bulletin of Don. - 2013. - No. 4.

[4] Ketova N.P., Ovchinnikov V.N. Institutes of development in multistructure economies of peripheral regions // Problems of forecasting. - 2014. - No. 2. - P. 68-76.

[5] Kushnarenko T.V. Strategy of transition to non-resource development of the multi-regional economy of the region / T.V. Kushnarenko. Thesis for sisk. degrees of Doct. econ. sciences. Access mode: https://rsue.ru/.

[6] Kushnarenko, T.V. The phenomenon of multiculturalism in the regional strategizing / T.V. Kushnarenko, L.G. Matveeva, O.A. Chernova // Ekonomika regiona [Economy of Region]. - 2016. - Vol. 12. - Iss. 3. press. 